\title{
Niche Construction Theory in Archaeology: A Critical Review
}

\section{Robert N. Spengler III ${ }^{1}$}

Accepted: 14 May 2021/ Published online: 4 June 2021

(C) The Author(s) 2021

\begin{abstract}
Over the past decade, niche construction theory (NCT) has been one of the fastestgrowing theories or scholarly approaches in the social sciences, especially within archaeology. It was proposed in the biological sciences 25 years ago and is often referred to as a neglected evolutionary mechanism. Given its rapid acceptance by the archaeological community, it is important that scholars consider how it is being applied and look for discrepancies between applications of the concept. Many critical discussions of NCT have already been published, but most of them are in biology journals and may be overlooked by scholars in the social sciences. In this manuscript, my goal is to synthesis the criticisms of NCT, better allowing archaeologists to independently evaluate its usefulness. I focus on the claims of novelty and differences between NCT and other approaches to conceptualizing anthropogenic ecosystem impacts and cultureevolution feedbacks. I argue that the diverse concepts currently included in the widereaching purview of NCT are not new, but the terminology is and may be useful to some scholars. If proponents of the concept are able to unify their ideas, it may serve a descriptive function, but given that lack of a testable explanatory mechanism, it does not have a clear heuristic function.
\end{abstract}

Keywords Niche construction theory · Darwinian Theory · Human behavioral ecology • Evolutionary ecology $\cdot$ Evolutionary theory $\cdot$ Gene-culture coevolution

Niche construction theory (NCT) is 25 years old (Laland et al., 1996, 1999, 2001; Odling-Smee et al., 2003; Laland \& O'Brien, 2010; O’Brien \& Laland, 2012). While many scholars have been slow to accept the ideas that it envelopes, others have embraced it enthusiastically. Scanning the literature, a few observations are evident: (1) The concept has expanded considerably from what was originally discussed by

Robert N. Spengler, III

Spengler@shh.mpg.de

1 Department of Archaeology, Max Planck Institute for the Science of Human History, Jena, Germany 
Laland et al. (1996) and Odling-Smee et al. (1996); (2) supporters of the framework do not have a unified doctrine; and (3) the concept is increasing in popularity within the social sciences, notably archaeology. Scholars have presented articles promoting the concept in conservation studies (Boogert et al., 2006), in archaeological theory (Laland \& O'Brien, 2010), in the origins-of-agriculture debates (O'Brien et al., 2012), in studies of human evolution (Laland et al., 2001), and psychology (Flynn et al., 2013). Given that evolutionary theory has been a prominent hallmark of all of these areas of study for nearly a century, it is important for scientists in these fields, especially archaeologists, to consider what novel insights this approach has provided to their field. In this article, I examine the ways scholars use the concept of NCT in the social sciences, focusing on (1) the originality of the concepts that it encompasses and (2) its usefulness as an epistemic tool for generating and/or testing ideas.

With a quarter of a century of promotional articles arguing for the novelty and usefulness of NCT, it is worth stepping back and examining the ways it has been applied (e.g., Laland et al., 1996, 1999, 2001, 2014, 2015, 2016; Odling-Smee et al., 2003; Laland \& O’Brien, 2010, 2015; O’Brien \& Laland, 2012; Odling-Smee, 2010; O'Brien et al., 2012; argumentum ad infinitum). These promotional articles often contain dramatic speech justifying the need for this concept in evolutionary discussions. As an example, "Culturally, niche-constructing humans cannot be just 'vehicles' for their genes... nor the passive 'playthings' of chance and necessity. Instead, we are bound to influence, but not control, our own future evolution, and the future evolution of other organisms in our shared ecosystems as well. That realization might eventually change not only how biologists, but also everyone else, perceives evolution and reevaluates their own existence" (Odling-Smee, 2010:202). Laland and O'Brien (2010:303, 312) state, "archaeologists need not be mere consumers of biological insights but can become important contributors to evolutionary theory." They also claimed, "NCT can be viewed as more in accord with the perspective of most archaeologists, who are highly attuned to the active agency of their subjects, than standard evolutionary theory" (suggesting archaeologists who choose not to adopt their framework are less attune). These are powerful words, and this writing style has attracted a strong congregation, but also deterred many scholars, who are not used to seeing such grandstanding in scientific writing. Gupta et al. (2017:491) recently stated "the manner in which niche construction theory is sought to be pushed in the literature looks more like an exercise in academic niche construction whereby, through incessant repetition of largely untenable claims, and the deployment of rhetorically appealing but logically dubious analogies, a receptive climate for a certain subdiscipline is sought to be manufactured within the scientific community." Given the abundance of promotional articles (as opposed to research articles seeking to test the theory), the critical responses are often overshadowed; therefore, it is worth evaluating whether the claims have proven accurate.

As I discuss subsequently, some promoters of NCT push for a broad all-inclusive definition (e.g., Laland et al., 2005, 2016); the resulting lack of specificity has created an increasingly inclusive concept. Furthermore, within the social sciences, the evolutionary feedback mechanism is often dropped; in doing so, the meaning of the term is expanded to include all adaptive and learned human behavior, roughly equivalent to how most scholars use the term culture (or artificial selection). To clarify, culture, defined as the broadly accepted social behaviors of a group of people, is usually 
adaptive and transmitted through social learning; therefore, all cultural practice is a niche-constructing process. Anthropology and Archaeology (especially since the formation of cultural ecology) are the study of human behavior and are, therefore, the study of cultural niche construction. Similar concerns have already been raised in the field of evolutionary biology or ecology, whereas an all-inclusive definition of niche construction encompasses all biotic aspects of natural selection. Ecology is the study of the relationship between organisms and the biotic and abiotic world around them and is, therefore, the study of NCT. NCT has been called "a new label for a wide variety of well-known phenomena" (Futuyma, 2017:1). As Smith (2013:114) put it, NCT "simply offers old wine in new bottles." I will further examine in the succeeding texts the ways NCT has been expanded to equate either cultural adaptation or selection.

While my goal in this paper is to provide a critical review, in the end, all scholars need to decide for themselves whether the concept of NCT has utility in their work. Many critiques of NCT have been published in the biological sciences (Adenzato, 2000; Brodie, 2005; Dawkins, 2004; Dickins, 2005; Futuyma, 2017; Gerbault, 2012; Gupta et al., 2017; Scott-Phillips et al., 2014; Wallach, 2016); however, given its growing popularity in the social sciences, I believe a synthesis of these critiques specifically for an archaeology audience is warranted. In this article, I open with a discussion of the intellectual trajectory of NCT and its predecessor theories; I specifically argue that the ideas encompassed within NCT are not new and were well developed in the biological sciences prior. Then I more deeply evaluate differences between ecosystem engineering and niche constructing. I also point out ways that the definition has expanded to become all inclusive in the social and biological sciences; finally, I evaluate the key case studies in archaeology, notably in the origins-ofagriculture debates. I end with some suggestions for scholars who choose to consolidate NCT into a unified archaeological approach.

\section{The Origins of NCT}

It is a reoccurring theme in the NCT promotional articles that the ideas it encompasses are divergent from other evolutionary theory (i.e., a new part of the extended evolutionary synthesis; Laland et al., 1999, 2000, 2014, 2015; Odling-Smee et al., 2003; Odling-Smee, 2010; Mesoudi et al., 2006; Danchin et al., 2011; Zeder, 2016, 2017, 2018; Müller, 2017). Niche construction is often referred to in this literature as a neglected evolutionary process, and many supporters claim that it is at odds with mainstream Darwinian thought. This claim is boldly epitomized in the title of the one detailed synthesis of NCT: Niche Construction: The Neglected Process in Evolution (Odling-Smee et al., 2003; see also Odling-Smee, 2010; Zeder, 2016). Additionally, these promotional claims often suggest that there was a recent revelation among a few biologists that niche-constructing processes are evolutionarily significant, usually tied to work by Lewontin. Laland et al. (2016:192) claimed: "the niche construction perspective was brought to prominence through the writings of Harvard biologist Richard Lewontin, although related ideas can be found in earlier work by Schrödinger (1944) and Waddington (1969)." The claims of novelty are used to emphasize the need for scholars to adopt this theory, as many of these scholars claim that current evolutionary theory is lacking. This claim of novelty is essential to the evaluation of its 
usefulness, as it has been one of the strongest promotional points. In this section, I argue that all aspects supported by proponents of the theory were well-studied processes prior to 1996, making up the foundation of the field of ecology. I further suggest that much of the critical revisionary rhetoric was used to promote NCT sounds like it came from Lewontin's criticisms of certain evolutionary biologists from the 1950s to 1970s and were well-accepted by the mid-1990s when NCT premiered.

\section{An Earlier Legacy of Thought}

The realization that organisms directly affect the survival and adaptive success of other organisms goes back at least to Humboldt, diverging from biologists of his time, whom he saw as too focused on form and not on ecological processes. He focused on the interaction of plants with their environment, discussing, what he called, the social organization of plants, viewing species that interact with each other as communities. He also presented one of the first discussions of human impacts on the environment (Humboldt et al., 2008 [1807]), although many of these concepts were already articulated by Hutton (1788), who also coined the term superorganism, which he used as akin to an ecosystem engineer. Likewise, the adaptive success of ecosystem engineering has been widely recognized since at least as early as Darwin $(1859,1881)$. Darwin (1881) wrote a book on the adaptive and evolutionary significance of earthworms constructing and maintaining their subterranean ecosystem. He was also fascinated by the evolutionary significance of mutualistic relationships between species (Darwin, 1877). Many early ecologists throughout the late nineteenth and twentieth centuries further developed the study of how organisms construct their own niche. Karl Möbius in 1877 coined the term biocenosis, essentially describing the evolutionary impacts that organisms have on other organisms. He was particularly interested in an organism's ability to construct its ecology, and he provided a detailed case study of oyster ecosystem engineering (Möbius, 1870, 1877). Warmington (1909), Tansley (1935), Vernadsky et al. (1997 [1926]), and many other early pioneers of the field of ecology explored the relationships between organisms and how they influence the environment around them.

The concept of an ecological niche as all the biotic and abiotic stressors acting upon an organism and that organism's place within the ecological milieu was laid out by a string of ecologists in the early 1900s. Elton (1927) explored the ecological changes associated with introduced invasive species, specifying how they modify the biotic stressors on themselves and the organisms around them (Elton, 1958). Vernadsky (1997 [1926]) built on Hutton's superorganism concept and also elaborated on Suess's (1904-1924 [1885-1909]) term biosphere, all of whom noted that organisms interact with biotic and abiotic materials around them. Fisher (1930) noted that when a population gets larger, it affects the availability of resources around it and decreases the overall fitness of the population (core Malthusian concepts from the late eighteenth century). He went on to observe that changes in allele frequencies within a population often lead to changes in the environment (Fisher, 1941). Hutchinson (1957) discussed an ecological niche as a continual transmission of energy and matter between organisms, and the ecological niche was the backdrop for his Ecological Theater. Mayr (1963) also discussed ways that behavior leads to the evolution of an organism and the environment around it and campaigned for a less gene-focused approach to 
evolution. As an architect of the Modern Synthesis, Mayr (2001) spent his career pushing for ecological and population-scale discussions of evolutionary processes.

The Prussian Darwinian intellects also presented variations of NCT more than 150 years ago. For example, Haeckel's ontology in Generelle Morphologie (Haeckel, 1866) elaborates how environmental factors, many of which were created by the organism itself, can direct the evolution of that species. The early Darwinian ecologists of Russia also made similar claims, for example, in 1886, Dokuchaev observed that soil is the construct of communities of organisms. The Baldwin Effect or Genetic Accommodation, presented in 1896, under the banner of "A New Factor in Evolution" (Baldwin, 1896), emphasized the evolutionary implications of learned behavior (i.e., cultural niche construction) or acclimatization, a view directly built upon by Waddington. But it is important to remember that both Waddington's Genetic Assimilation and Baldwin's Genetic Accommodation rely on natural selection and are, therefore, Darwinian and not Lamarckian. Interestingly, the incorporation of NCT into the extended evolutionary synthesis has often been an acknowledgment of neo-Lamarckian ideas (although quite diverged from those of Lamarck himself). Many scholars (Laland et al., 2014, 2015, 2016; Odling-Smee, 2010; Odling-Smee et al., 2003; Zeder, 2016) clump niche-constructing processes in with epigenetics as examples of an organism passing evolutionarily significant factors (ecosystem inheritance) onto its offspring. The inheritance of behavior, whether learned and transmitted, as through language or genetically encoded, is a basic premise in Darwinian evolution and was emphasized well over a century ago by Baldwin (1896).

\section{Gene-Culture Coevolution}

Many other more recent evolutionary biologists have also presented roughly equivalent concepts to the idea of cultural niche construction, such as Dawkins's (1982) Extended Phenotype, where he used a beaver dam as a case study and depicted a beaver on the book cover. The links between culture and evolution were laid out much earlier by Dawkins (1976), Wilson (1978), and Cavalli-Sforza (1973) and clearly influenced the development of gene-culture coevolutionary theory. In 1996, the same year that they presented the dual seminal NCT papers, Feldman and Laland (1996) published a synthesis of gene-culture coevolutionary theory, which already had more than two decades of scholarly debate backing it. As there is considerable overlap between the three 1996 papers, it seems likely that their ideas originated from this earlier scholarship, which essentially states the same things as their NCT (when applied to humans). Gene-culture coevolutionary theory was originally developed through a series of books in the early 1980s, notably Lumsden \& Wilson's (1981) Gene, Mind, and Culture and Cavalli-Sforza and Feldman's (1981) Cultural Transmission and Evolution.

The core idea held among these scholars is that culture, defined by them as all socially transmitted behavior (paralleling most uses of cultural niche construction), plays an important role in driving human evolution. Taking the approach further, the dual aspect of human evolution and the feedback mechanism between culture and biology were later labeled dual inheritance theory (Boyd \& Richerson, 1985). While lactase persistence is consistently the main case study provided in this literature, food processing, notably grinding and cooking, is also discussed. In fact, as I note in the succeeding texts, the three main case studies used in early NCT arguments were taken 
directly from gene-culture coevolutionary theory. Many of these ideas trace back to earlier discussions of the ways that culture and constructed environments create selective feedbacks on humanity (e.g., Dawkins, 1976). Two decades prior to the inception of NCT, Dawkins (1976:189-201) stated: "Most of what is unusual about man can be summed up in one word 'culture'.... Cultural transmission is analogous to genetic transmission in that, although basically conservative, it can give rise to a form of evolution." In fact, Dawkins goes on in great length to discuss the role of culture in selection for humans, critiquing arguments of overly gene-focused approaches to human behavior. In many ways, NCT, as applied to humans, is a rebranding of dual inheritance theory and gene-culture coevolutionary theory. Most social scientists feel that Wilson (1975) initially took these links too far in sociobiology (they often label him a genetic determinist), but he continued to develop the idea of gene-culture coevolution, focusing increasingly on culture in later publications (Wilson, 1999). Likewise, an insular group of scholars continues to develop dual inheritance theory, often echoing the same statements as proponents of NCT (Boyd \& Richerson, 2005; Richerson \& Boyd, 2008).

Jones et al. (1994:373) introduced the concept of ecosystem engineering 2 years prior to the formalization of NCT, presenting it as a term used to describe the myriad ways an organism impacts the ecosystem around it and changes the survivability of itself and other organisms. Jones et al. (1994) fix their concept into a large body of literature focused on animals constructing their environments or niches, and most importantly for the present discussion, they also provide detail on human nicheconstructing processes. I will elaborate more on the concept of ecosystem engineering in the subsequent texts, but like dual inheritance theory, it continues to be applied by scholars saying the same things as proponents of NCT (Erwin, 2008; Jones et al., 1994, 1997, 2010; Wright \& Jones, 2006). Despite a long intellectual lineage of thought leading up to NCT and rich parallel lines of inquiry, proponents of NCT often present their ideas as either novel concepts or as part of a truncated lineage of thought, tied to one or two specific founders (Table 1).

\section{A Lineage of Thought}

Given that proponents of NCT have embedded themselves into the dynamic theoretical movement referred to as the extended evolutionary synthesis, it is not surprising that many of them trace their genesis not to Darwin or Humboldt, but to Waddington's Exploitive Systems (e.g., Odling-Smee, 2010; Laland et al., 2016 [they also link their intellectual ancestry less clearly to Schrödinger]). Waddington (1968, 1969), as with many biologists during the eclipse of Darwinism, sought to link Darwinian and Lamarckian ideas through his concept of genetic assimilation. Therefore, when scholars trace the intellectual lineage of NCT to Waddington (1968), they link themselves into a larger wave of theoretical reform. In reality, Waddington saw himself as a Darwinian scholar but called for an extended evolutionary synthesis, even as the Modern Synthesis was still being developed (Wilkins, 2008). Lewontin (1978, 1982, 1983) is also often credited as the founder of NCT; however, he did not use the term niche construction and did not provide a clear definition for the concept. He did link his view of organisms constructing the environment to Waddington's Drosophila studies and a deeper legacy of criticism towards other Darwinian scholars. 
Table 1 A summary of some of the roughly synonymous theories that currently exist and are actively being utilized to explain the links between human culture and evolution

\begin{tabular}{|c|c|c|}
\hline Theory & Description & Reference \\
\hline $\begin{array}{l}\text { Dual inheritance } \\
\text { theory }\end{array}$ & $\begin{array}{l}\text { "a second system of inheritance, culture, is an important } \\
\text { determinant of phenotype in our species" }\end{array}$ & $\begin{array}{l}\text { Boyd and Richerson } \\
\quad(1985: 127)\end{array}$ \\
\hline $\begin{array}{l}\text { Gene-culture } \\
\text { coevolutionary } \\
\text { theory }\end{array}$ & $\begin{array}{l}\text { "These models have been employed to examine the } \\
\text { adaptive advantages of learning and culture, to } \\
\text { investigate the forces of cultural change, to partition } \\
\text { the variance in complex human behavioral and } \\
\text { personality traits, and to address specific cases in } \\
\text { human evolution in which there is an interaction } \\
\text { between genes and culture." }\end{array}$ & $\begin{array}{l}\text { Feldman and Laland } \\
\text { (1996:453); Lumsden \& } \\
\text { Wilson's (1981) }\end{array}$ \\
\hline $\begin{array}{l}\text { Extended } \\
\text { phenotype }\end{array}$ & $\begin{array}{l}\text { "An animal's behaviour tends to maximize the survival } \\
\text { of the genes for that behaviour, whether or not those } \\
\text { genes happen to be in the body of the particular } \\
\text { animal performing it." } \\
\text { "... having extended phenotypic effects, consisting of all } \\
\text { its effects on the world at large, not just its effects on } \\
\text { the individual body" }\end{array}$ & Dawkins (1982:xiii, 4) \\
\hline $\begin{array}{l}\text { Ecosystem } \\
\text { engineering }\end{array}$ & $\begin{array}{l}\text { "Ecosystem engineers are organisms that directly or } \\
\text { indirectly modulate the availability of resources to } \\
\text { other species, by causing physical state changes in } \\
\text { biotic or abiotic materials." }\end{array}$ & Jones et al. (1994:373) \\
\hline
\end{tabular}

Note that most scholars studying the ways human behavior and cultural inheritance drive human evolution do so without using an organized theory

While the concept of niche construction long predates Waddington or Lewontin, the term was first formalized in 1996, when Odling-Smee et al. (1996) and Laland et al. (1996) laid out identical definitions. In twin seminal works, they envisioned niche construction loosely as "organisms, through their metabolism, their activities, and their choices, define and partly create, [and partly destroy] their own niches" (Laland et al., 1996:293; Odling-Smee et al., 1996:641). This definition is repeated throughout the literature (e.g., Odling-Smee et al., 2003:419). In both cases, the strawman the authors attack is really the Red Queen, both citing Van Valen (1973). Although Van Valen's model of evolution had already been heavily criticized for its simplicity by this time (Smith, 1976; Vrba, 1993), and Van Valen actually specified that his model was a theoretical simplification of reality. Interestingly, Van Valen (1973) created his imaginary ceteris paribus world in order to combat overly climate-focused models of evolution, noting that organisms drive extinction and, therefore, evolution through their behavior. In his view of macroevolution, organisms are continually one-upping each other, and this model has been colloquially referred to as the evolutionary arm's race. Arguably, pointing the crosshairs at the Red Queen missed Lewontin's mark. It is important to point out that the current broad definition of NCT actually encompasses all processes that Van Valen (1973) was campaigning for. Lewontin's critique was that some architects of the Modern Synthesis were making mathematical equations to explain evolution that was overly gene focused, although the same comments had already been made by numerous founders of the Modern Synthesis, notably Ernst Mayr $(1963,2001)$. At a time before computer modeling, simplified mathematical equations 
or parsimonious models were readily used in population genetics (e.g., Lumsden \& Wilson's, 1981). Lewontin's critique was that these models did not account for the great diversity of evolutionary factors - everyone, including the modelers, agreed, but the debate was really over the merits of using the principle of parsimony.

While it is speculation, the linkage to Lewontin may also have been an attempt in the 1990s to declare allegiances in, what at the time was called, the Darwin Wars, primarily between Dawkins and Gould. One prominent fixture of the Gouldites was the claim that evolution needs to be considered on an organismal scale, as opposed to the gene scale. This critique is often simplified to the statement that mainstream evolutionary biology has become too gene focused. In reality, the debates were far more complex, and no one really believed that a genome directly codes for a phenotype. Some of the language used in the early NCT promotional papers sounds like it has been taken from critical evaluations of Dawkins's Selfish Gene theory or the idea that organisms are "just 'vehicles' for their genes" (Odling-Smee, 2010:202). But many scholars, including Wilson, Mayr, and Gould, had already spoken out against the reductionist program and the idea of the gene as the unit of selection. These debates reached a pivotal point with the joint Gould and Lewontin's (1979) critique of adaptationism and their description of the spandrels of San Marco. In fact, even Dawkins (1982) opened his discussion with a summary of critiques of adaptationism and genetic determinism. But of course, by the end of the 1960s, there were no real genetic determinists left, and Dawkins noted that the continuing rhetoric against genetic determinism transformed into an attack on a largely nonexistent "super-deterministic view" of genes that could override environmental triggers. On the other side of the coin, even the most culture-focused scholars recognized a complex interplay between genes and environment; Geertz (1973:44) summed the situation at the time up well, "we need to replace the 'stratigraphic' conception of the relationship between the various aspects of human existence with a synthetic one; that is, one in which biological, psychological, sociological, and cultural factors can be treated as variables within unitary systems of analysis." Linking NCT to the extended evolutionary synthesis seems to suggest that the proponents of NCT were tethering themselves to a larger debate that had been ongoing for decades.

The choice of Lewontin as the founder of NCT and the rejection of earlier literature by Dawkins, Wilson, and others may also have had more complex political motivations. The rather infamous conflict between Lewontin and Wilson went far beyond an academic feud. In fact, a critical breakdown of this academic conflict has rather astutely placed its roots in "epistemological and moral realms," as opposed to scientific interpretations (Segerstrale, 1986:53). Again, Lewontin's issue was primarily over whether it was appropriate at that time to use simplified mathematical equations in the modeling of evolution; additionally, his attack on sociobiology was rooted in a distain for all suggestions of gene-behavior linkages (Segerstrale, 1986). If the narratives for explaining the Lewontin and Wilson controversy are accurate, then Lewontin would have strongly opposed any claim that human behavior is genetically programed; as this is foundational to NCT, he would theoretically oppose NCT. Interestingly, Lewontin, in many ways, was following trends in the field, just as many other scholars mentioned in this paragraph did, from more gene focused prior to the 1970s to greater recognition of the complexities of the gene-environment interactions. Dawkins (1976:30) famously stated that Lewontin "traveled on his road to Damascus," as a former adaptationist (Lewontin 1967), and turned evangelical anti-adaptationist (Gould 
\& Lewontin, 1979). Oddly, Lewontin opposed all claims that any part of behavior could have a genetic basis; Wilson (1999), on the other hand, went on to continue claiming that human culture can direct human evolution, a foundational aspect of NCT (both protagonists are currently 91 years old and do not appear to have changed their stances or adopted NCT). Ultimately, the active linkage of NCT to Lewontin and supporters of his side of the debate and the rejection of Wilson and the writings of his supporters may be drawing on deeper emotional ideologies. Alternatively, when the founders of NCT pulled their ideas from the writings of Lewontin, they might have inadvertently resurrected this deeper theoretical debate.

The mythological lineage of thought from Waddington through Lewontin to OdlingSmee and Laland is a reoccurring theme in the literature (Laland et al., 1996; Laland \& O'Brien, 2010; Odling-Smee et al., 1996, 2003). The claims of a lineage of intellectual thought are almost always accompanied by accusations of errors, limitations in, or neglected aspects of what they call standard evolutionary theory or the neo-Darwinian paradigm (Blancke \& Denis, 2018; Danchin et al., 2011; Laland, 2017; Laland et al., 1999, 2001, 2014; Müller, 2017; Odling-Smee et al., 2003; Zeder, 2015a, 2016, 2017, 2018). These claims have been picked up and hyperbolized in popular science as well (Fodor \& Piattelli-Palmarini, 2010). Evolutionary ecologists have repeatedly disputed such claims (Brodie, 2005; Futuyma, 2017; Gupta et al., 2017), noting that there is a long legacy of studying these processes in ecology and evolutionary biology (as I outlined earlier). These back-and-forth debates over the intellectual novelty of NCT concepts have been a prominent source of continual publication and tension. Ultimately, in a surprising response to the two decades of debate over novelty, Feldman et al. (2017:505) recently disavowed all claims that niche construction has been presented as a neglected evolutionary process, noting that "NCT has never made the claim that the fact that organisms engage in niche construction is neglected - not once, let alone repeatedly - as is apparent to those that have read our book and papers carefully." Adding to this, the recent work by Laland $(2017,2018)$ now directly traces an intellectual lineage to Darwin. The new statement that niche construction is part of a widely recognized set of evolutionary processes across the social and biological sciences undermines the need for a revisionary theoretical framework or its incorporation into any form of an extended evolutionary synthesis.

\section{NCT and Ecosystem Engineering}

Understanding the difference between ecosystem engineering (Erwin, 2008; Jones et al., 1994, 1997, 2010; Wright \& Jones, 2006) and niche constructing is key for evaluating the usefulness of one concept over the other and determining whether there is a need for the theoretical discussion that has developed around both. However, there seems to be no consensus on the exact definition of either term or whether the two terms refer to the same general ecological processes. It is also important in science to be cognizant of whether terms are simply catchphrases or whether they have a novel and effective use. As a suggestion for spotting buzzwords in scholarly literature, often after removing the word or phrase from a sentence (or replacing it with a simpler word), the sentence retains its scholarly value. As one case study, Odling-Smee (2010:194) noted, building on Darwin's (1881) claim that rather than evolve traits for terrestrial life, 
earthworms "have apparently modified their environments by niche construction to suit themselves, instead of evolving new physiological adaptations." The question then is whether the statement would be equally as accurate after removing "by niche construction." This utility test can be applied to most of the NCT literature.

Odling-Smee (2010) claimed that ecosystem engineering and niche construction refer to different processes, but he often uses both in the same sentence. He stated, "if the ecosystem engineering consequences of niche construction do persist in the environments of populations for multiple generations - there can be evolutionary consequences" (Odling-Smee, 2010:194). Again, the trick of removing a phrase and testing the viability of the resulting sentence is worth considering here. In contrast to OdlingSmee (2010), Silver and Di Paolo (2006) claimed that ecosystem engineering and niche constructing are connected terms; Laland and Boogert (2010:732) claimed that "Niche construction revolves around the same concept as 'ecosystem engineering" " and further state "we treat 'niche construction' and 'ecosystem engineering' as synonyms." Albuquerque et al. (2019:50) claimed that ecosystem engineering and niche construction resemble each other, but they pose that NCT goes further in its assumption that the constructing actions "modify or generate selective pressures that feed back to the organisms." Many other scholars also argue that the terms are synonymous, for example, Laland and O'Brien (2010:306) and Boogert et al. (2006):570-571; also nearly identical with O’Brien \& Laland, 2012:436) all repeat:

A focus on organisms' modification of environments is also central to the concept of "ecosystem engineering," which was introduced to ecology by Jones et al. (1994, 1997). Here, "ecosystem engineering" and "niche construction" are considered synonyms, although the phrase "ecosystem engineering" is used mainly in ecology, whereas "niche construction" is the term adopted by evolutionary biologists. Jones et al. (1994) drew attention to a lack of ecological research effort dedicated to organisms that modulate the availability of resources and habitat to other species by causing physical state changes in biotic or abiotic materials.

Boivin et al. (2016) use both of those terms, as well as "created novel ecosystems," "maintenance of ecosystems services," and "human agency on ecosystems," all seemingly interchangeably. While there is, of course, room for synonyms, the lack of agreement in usage among key proponents is disconcerting.

Increasingly, other ecologists dealing with humans appear to be stepping beyond this debate completely. Among these scholars, many other terms or phrases are used as apparent synonyms. For example, Sullivan et al. (2017:1) discussed humanity's "roles as ecological actors" and present "humans as trophic regulators." Most evolutionary ecologists studying anthropogenic evolutionary drivers have left behind NCT and are discussing eco-evolutionary dynamics broadly (e.g., Steffen et al., 2007; Alberti, 2015; Waters et al., 2016; Alberti et al., 2017a, b; Hendry et al., 2017; Pelletier \& Coltman, 2018). Ceballos et al. (2020) referred to humanity as the Sixth Mass Extinction, and many scholars have started adopting the term Anthropocene to recognize the dramatic effects humanity has had on the planet. Some scholars have started referring to humans as "super-predators" (Darimont et al., 2015; Pelletier \& Coltman, 2018), suggesting that humans have the evolutionary ability to change entire ecosystems and niches of all 
organisms in those ecosystems. Given that so many scholars are currently studying human niche-constructing processes without using the requisite nomenclature of NCT, it raises the question of whether an organized theory is necessary or if it is just a repetition of the stated goals of ecology and evolutionary biology — and when humans are involved: cultural ecology, environmental archaeology, ecological archaeology, and human behavioral ecology, broadly speaking.

\section{An Expanding Concept}

Any scientific theory requires clear parameters of what it entails, and how it could, hypothetically, be falsifiable, or it is not a scientific theory (Falsificationism; Popper, 1968). The Popperian philosophy of science states that a scientific theory must forbid things from happening (although he was fixated on the predictability of physics). NCT consists of a single statement, and its parameters have continued to expand since its inception, creating an all-encompassing concept. Okasha (2005) called for a narrowing of the definition to exclude the modification of selective pressures on one species by another (as this already encompasses most of the field of ecology). Sterelny (2005) also called for more specificity in the definition to exclude incidental changes in the environment, such as a plant changing oxygen levels through respiration. Other attempts at narrowing down the definition have failed too (e.g., Kendal et al., 2011; Smith, 2013), as some NCT advocates have adamantly rejected attempts at specificity (e.g., Laland et al., 2005). Despite the lack of clarity in the expanding concept, increasingly inclusive applications are being advocated: "The definition of niche construction is purposely broad, encompassing how the selection is affected both by physical changes that organisms bring about in their environments ("perturbational niche construction') and by when they move in space and are exposed to new conditions ('relocational niche construction')" (Laland et al., 2016:193). Equally broad-sweeping definitions have consistently been presented, such as "niche construction is the process by which organisms bring about changes in their local environments" (Scott-Phillips et al., 2014).

Given an all-encompassing definition, niche-constructing processes include all biological activities from respiration and transevaporation to predation, walking, driving a car, or building the pyramids. As Odling-Smee and Turner (2011:283) claimed, NCT is "a coherent evolutionary theory of the natural-built environment." In application, it seeks to replace the fields of ecology or evolutionary biology, but it does not actually contribute anything new to these fields. When applied in biology, NCT encompasses all ecological factors and most evolutionary drivers; when applied in the social sciences, NCT includes all cultural and social practices. Again, this broad definition engulfs all Red Queen dynamics, including parasitic relationships and herbivory, along with all mutualistic interactions broadly - essentially all biological activity (Laland \& O'Brien, 2010; Turner, 2016). Presumably, Laland and O'Brien (2010:318) foresaw this unraveling of the definition or were already witnessing it in 2010 when they stated: "Much though we would like to see archaeologists using niche construction, we would not like this to be an alternative form of 'just-so' evolutionary storytelling, nor would we feel comfortable if NCT were so open and vague that it could explain any conceivable dataset. To be useful, it must encourage rigorous 
science." Despite their cautionary words, they do not specify what they mean by storytelling and provide no criteria for preventing this unraveling. Their prophetic warnings may have rung true.

In the seminal publications on NCT (Laland et al., 1996; Odling-Smee et al., 1996), chemical responses and nutrient cycling by plants are considered niche constructing. The most frequently used case studies in these early discussions include earthworms modifying soil, badgers digging burrows, and spiders constructing webs. While these scholars were already using the concepts of ecosystem inheritance or ecological inheritance, their repeated use of a spider web or tool used by finches indicates that they did not see this form of inheritance as a prerequisite for inclusion into the framework (Laland et al., 1999). Odling-Smee (2010) uses a bird nest as a case study for an ecological inheritance, but while it assists in the juvenile development stage of the bird, it is not passed on to the next generation after they leave parental care. Including parental care in the ever-expanding definition of NCT would mean that the endosperm production of a seed, as provisioning, or the production of an egg is niche construction. Many scholars are quick to point out that ecological inheritance is different from biological inheritance in the NCT purview (Laland \& O'Brien, 2010; Odling-Smee et al., 2003) and that the concepts are really presented as metaphors in the same way some archaeologists discuss cultural evolution. Likewise, if predation is a niche-constructing process, then predation pressure leading to adaptive evolution brings us face to face again with the Red Queen. Increasingly, NCT has expanded to include natural, artificial, and sexual selection, as well as biological, cultural, and ecological inheritance.

Continuing down Carroll's rabbit hole, other applications of NCT lead to more divergent questions. If the transmission of learned behavior is ecological inheritance (Creanza et al., 2016; Reader \& Laland, 2002), then does this approach not return to the question of all culture being a niche-constructing process - culture, by definition, is learned and transmitted. Alternatively, if innate or biologically programed behaviors count as ecological inheritance, then the process being described is genetic inheritance possibly through genetic accommodation, vis-à-vis Baldwin and the Modern Synthesis. Expanding the definition even further, all movement, mobility, and relocation have been included in NCT. The concept of "relocational niche construction" appears to include dispersal, migration, habitat selection, and presumably any process of mobility where organisms relocate in space to modify their experienced environment (OdlingSmee et al., 2003). Relocational niche construction appears to include everything from pollen and seed dispersal to a person walking down the street (Laland et al., 2016). At least one scholar has included the simple process of maintaining homeostasis essentially, being alive. Turner (2016) claimed that the process of being alive is, by definition, a niche-constructing process. Turner's (2016) concepts of extended physiology and extended homeostasis transcend the NCT discussion and turn it into an existential debate over what it means to be alive. While clearly drawing on Dawkins, Turner (2016) also resurrected Schrödinger's discussion of entropy in What is Life? and Lovelock's Gaia Theory - all, loosely, earlier iterations of an open-ended NCT.

As a limited sampling of the highly divergent ecological processes that have been incorporated into the ever-expanding realm of NCT: yeasts (Saccharomyces cerevisiae) producing alcohol (Buser et al., 2014), pine trees building up needle litter (Schwilk, 2003), changes in germination times for plants (Donohue, 2014), and seed-dispersal 
mechanisms (Donohue et al., 2005). All social behavior, human or nonhuman, constitutes an interaction between at least two organisms and is, therefore, part of NCT (Saltz \& Foley, 2011; Saltz \& Nuzhdin, 2014). Taking this even further, scholars have singled out the sexual selection (Albuquerque et al., 2019; Saltz \& Foley, 2011), cooperative (Connelly et al., 2016), and aggressive (Saltz \& Foley, 2011) behaviors as particularly strong niche-constructing processes. In fact, the development of violent actions in humans has been linked to NCT (Broughton et al., 2010). Similarly, if developmental plasticity in plants is considered niche construction (cf. Donohue et al., 2005), then, in theory, all epigenetic, acclamatory, developmental, and regulatory changes in organisms are niche-constructing processes. All-natural, artificial, or sexual selection is part of NCT, leaving one to wonder if NCT has expanded to encompass all Evolutionary or Darwinian Theory.

These critiques of the all-encompassing arms of NCT are not new. In a review of Odling-Smee et al. (2003), Brodie (2005:249) stated: "Few ecologists or evolutionary biologists would be surprised to learn that organisms interact with their environment in ways that change both the environment and the organism's perception of it. What, then, is the importance of defining a new concept to encompass all such actions?" He goes on to observe that the "existing theoretical frameworks in ecology and evolution encompass much of what the authors seek to capture in niche construction, though clearly not under a single unified banner" (Brodie, 2005:250). Dawkins (2004) made a similar critique, noting that the concept of NCT becomes moot when the advocates expand it to include all biological processes. Ultimately, the expansion of the concept of NCT has resulted in a milieu of ideas, no unified parameters, and a universally applicable term that has no evident function.

\section{Dropping the Evolutionary Feedback}

Another aspect of the expansion of NCT has been whether the evolutionary feedback mechanism is an essential component. Arguably, the aspect of NCT that originally sets it apart as a discrete theory was the idea that through niche-constructing processes, organisms can change their own evolutionary trajectory (Odling-Smee et al., 2003). The 1996 papers were advocating for greater awareness of the evolutionary ramifications of these niche-constructing processes on the organism that partook in the niche construction - the feedback mechanism. Silver and Di Paolo (2006) step beyond hypothetical discussions of selective pressures and claim that the evolutionary significance of NCT rests in the fact that behaviors of niche construction can be fixed into a population by generating disequilibrium between the alleles for that behavior and the alleles whose fitness depends on the modified resources. This idea that covariance between fitness and phenotype builds up over time was part of Brodie's (2005) critique and has subsequently been incorporated into the theoretical framework (Matthews et al. 2014). While many scholars adamantly emphasize the gene-culture coevolutionary aspect of the NCT framework (e.g., Laland et al., 1996, 1999, 2001; Laland \& O'Brien, 2010; OdlingSmee et al., 2003; Odling-Smee, 2010; Ihara \& Feldman, 2004; Hui et al., 2004; Boni \& Feldman, 2005; Borenstein et al., 2006; Silver \& Di Paolo, 2006; Lehmann, 2008), other scholars leave it out completely. When NCT is applied in the social sciences, especially in archaeology, the prerequisite of evolutionary feedback is almost always ignored. 
In the famous beaver dam analogy, the ecological consequences of the process of building a beaver dam on the willow trees living on the tangled bank or the crawfish living in the stream are not novel (Moore, 2006; Naiman, 1988; Naiman \& Rogers, 1997). The concept of interest was that the beaver could affect the survival of its own offspring through dam construction. Following this, generations of beavers repeating the same behavior can affect the allele frequencies for the trait of dam building. OdlingSmee (2010:194) stated: "the ecosystem engineering consequences of beaver niche construction may still be exclusively ecological unless they persist in the environments of populations for enough generations to allow any modified natural pressures they produced to cause the subsequent evolution of a population." Essentially, a beaver dam, in and of itself, is not representative of NCT; if the behavior is not maintained and repeated for enough generations, it will not result in evolutionary ramifications for the beaver population. NCT claims to be an evolutionary theory, and niche construction is an ecological process. Therefore, the beaver dam must create wetlands that persist for millennia to be included in NCT. Additionally, evolution is a population phenomenon (although selection usually occurs on the organismal level; Mayr, 2001; Wilson, 1999). If niche construction is to be thought of as an evolutionary phenomenon, then it needs to be discussed on a population scale and should not be conceptualized on the individual level, such as a single farmer turning over her field. This way of thinking is in direct conflict with that of many social scientists, especially archaeologists.

Given that so many published case studies within NCT do not discuss the evolutionary feedback, and the advocates do not specify if it is a prerequisite, it is unclear how to differentiate between NCT and niche construction. Niche-constructing processes are a well-accepted aspect of evolutionary ecology, and there is no need to construct a separate branch of evolutionary thought to include them. The conflation of the term niche construction to automatically equate NCT is problematic, especially within archaeology. As a population-scale process, scholars choosing to use the terminology need to think of behaviors that are repeated regularly by all members of a population. As an evolutionary phenomenon, the behavior has to reoccur for an evolutionarily significant duration. It should also be illustrated that the process causes measurable change (whether shown phenotypically or genetically) within the population conducting the behavior. Without meeting these criteria, the behavior should probably not be included in NCT. With these criteria in mind, we can look at some examples of application in the social sciences.

\section{Applications in the Social Sciences}

There have been numerous critical publications on NCT in the biological sciences, but only a few attempts to critically evaluate its effectiveness in the social sciences, for example, Wallach (2016):2595; also see Adenzato, 2000; Gerbault, 2012) concluded: "While NCT may serve as a descriptive framework for these [cultural] phenomena, it cannot be said to explain them in any substantive sense. Especially disturbing is NCT's failure to account for differing developments in very similar situations, and to facilitate evaluation and discrimination between divergent and contradictory causal accounts of particular phenomena." Additionally, Gerbault (2012:453) noted that for humans "niche construction happens all the time, everywhere, this questions how useful a 
phenomenon that occurs in every situation is for understanding the evolution of a system." Futuyma (2017:4) recently noted that "studies that identify themselves with niche construction have been mostly theoretical, and mostly addressed to cultural niche construction, especially by humans." Many scholars have already recognized that NCT does not explain human behaviors, but in some cases, these scholars argued that there is still utility for the terminology to be used as a philosophical tool (Adenzato, 2000; Godfrey-Smith, 2000; Townsend, 2000). In my examples of application in the succeeding texts, I try to avoid cases where scholars simply use the nomenclature of NCT but not the associated explanatory framework (e.g., Sterelny, 2005, 2007). Given the fact that this concept is growing in popularity in the social sciences, especially archaeology, but is not growing in the biological sciences (Futuyma 2017), social scientists need to be especially reflective. West et al. (2011) showed that evolutionary concepts are often misapplied in human studies, largely because of the isolation of anthropology/sociology from evolutionary biology. Recognizing this alarming legacy, it is important that scholars in the social sciences are hyper critical of their use of terminology.

Applying the expanded definition of NCT to humans includes all social behavior (Saltz \& Nuzhdin, 2014), everything from aggressive behaviors (Saltz \& Foley, 2011) to cooperative behaviors (Connelly et al., 2016). Scholars have noted that learning and the transmission of ideas is a niche-constructing process; this apparently includes language, songs, and all other aspects of cultural expression (Creanza et al., 2016; Reader \& Laland, 2002). Ihara and Feldman (2004) noted that kin and family structure are defined by niche construction. Other scholars have argued that the development of social inequality, intergenerational wealth transfer, and the formation of social hierarchies are all niche-constructing processes (Shennan, 2011). In fact, scholars have pointed out that following this concept of NCT, all social institutions are nicheconstructing processes (Shennan, 2011). Applying the concept of relocational niche construction, seed dispersal, predator avoidance, hunting, and simply walking are all under the all-encompassing umbrella of NCT. While the papers apparently have not been written yet, the following anthropogenic processes cause external change and are, therefore, niche construction: fermentation, mining, irrigation, planting, conservation, reproduction, applying sunscreen, driving a car, riding a horse, arguing, cleaning, swimming, crying, screaming, throwing, and engaging in a ritual.

Reader and Laland (2002) emphasized that tool use is niche construction. Others have pointed out that cooking is a niche-constructing process (Wollstonecroft, 2011). O'Brien and Bentley (2015) noted that food storage is also a niche-constructing process. Smith $(2007,2011,2015)$ argued that farming and the domestication of plants and animals are niche-constructing processes. Spengler (2015) noted that maintaining a mobile pastoral economy is a niche-constructing process. Other scholars have also argued that herding animals are a niche-constructing process (McClure, 2015). Yet other scholars have discussed the burning of forests and fishing as niche-constructing processes (Mohlenhoff \& Codding, 2017). Odling-Smee and Turner (2011) singled out architecture, specifically artistic construction, therefore, seemingly implying that "art," broadly speaking, is a niche-constructing process. Presumably, they would also include utilitarian domestic structures. Albuquerque et al. (2019) provided the example of overharvesting Himalayan lotuses (Saussurea spp.) leading to a reduction in specimen size, research conducted by Law and Salick (2005), or anthropogenic habitat loss 
leading to reduced genetic diversity in the Atlantic Forest Jaguar (Panthera onca), as shown by Haag et al. (2010). They take the topic of "cultural niche construction" even further noting that what they call "cultural evolution" (apparently as a biological process) is also part of the all-encompassing framework of NCT (Albuquerque et al., 2019:53). Some scholars claim that NCT explains essentially everything humans have done from the Pleistocene through the Holocene (Watkins, 2017).

Given that the social sciences are occupied with the study of social behavior and the all-encompassing definition of niche construction theory includes all social behaviors, all social scientists are, in effect, niche-construction scientists. One of the greatest shortcomings of NCT in the social sciences is the fact that it clumps all behaviors that humans engage in under one term and does not specify between conscious and unconscious processes (Mohlenhoff \& Codding, 2017). For example, if inadvertently overharvesting a wild resource and carefully maintaining that wild resource are equally weighed niche-constructing processes, then the intentionality, motivation, and thought that most archaeologists/anthropologists are interested in understanding are lost. Humans are constantly creating novel ecosystems and applying stress to the organisms around them (McDonnell \& Hahs, 2015). Creating a solitary term to describe the complexity of everything that humans do could be construed as standing in direct opposition to an anthropological approach. This term combines all possible motivating factors of human behavior, and it does not recognize human intentionality or agency. A single term that combines everything from building a house to breathing does nothing to forward archaeological studies.

There has been nearly a century of rich theoretical debate linking archaeology and ecology, prominently involving cultural ecology (Trigger, 1971). The idea, within the field of archaeology, that culture is adaptive and has ecological ramifications harkens back at least to Childe's Man Makes Himself. Childe (1936:20) stated, "In human history, clothing, tools, weapons, and traditions take the place of fur, claws, tusks, and instincts, in the quest for food and shelter. Customs and prohibitions, embodying centuries of accumulated experience and handed on by social tradition, take the place of inherited instincts in facilitating the survival of our species." There have been many attempts at creating consilience between biology and the social sciences, often focusing on the evolutionary origins of cultural practices or the evolutionary consequences of human behavior (e.g., Blancke \& Denis, 2018; Slingerland, 2012; Wilson, 1999). Even scholars who argue that culture is not innately adaptive note that cultural traits will only persist if they are symbiotic with, rather than parasitic on, humans (Dawkins, 1976; Dennett, 2017). The recognition that cultural behaviors allow humans to more rapidly adapt to new environments than evolutionary change is a core concept in archaeology, and these adaptations can be passed along through teaching and learning - a cultural inheritance system. Therefore, all of the ideas encompassed by discussions of cultural niche construction have already been explored and discussed in great detail by archaeologists for nearly a century. Ingold, 2007:17) pointed out that certain NCT proponents neglect to engage with social scientists or their theories, likening it to Victorian anthropologists treating the people they studied like "savages" and then chastising them for being so. Ingold claims that social scientists have become the "new savages."

The definition of what constitutes the NCT framework has come to encompass all human culture, often referred to as cultural niche construction. Arguably, the usefulness of NCT is most clearly expressed by the recent trend among its strongest 
supporters to drop the "niche construction" from their discussions of "cultural niche construction" (Whiten et al., 2017:7777). One of the seminal scholar who pushed the hardest to get NCT adopted in the social sciences, arguing that what made humans different from all other animals was their niche-constructing ability (Laland et al., 2016; Laland \& O'Brien, 2010; O'Brien \& Laland, 2012), changed his narrative in 2018, claiming that culture is what makes humans unique (Laland, 2017, 2018). In replacing cultural niche construction with the word culture, his narrative reads more clearly; however, what he then argues is already the basis of the fields of anthropology and archaeology. In his revised narrative, Laland (2018) claimed that culture led to the domestication of plants and animals, culture led to all human-induced environmental impacts, and culture is a set of learned and transmitted behaviors. Ultimately, after 25 years of campaigning, one of the top advocates of NCT appears to have recognized that what he was arguing is already being studied by thousands of scholars around the world - under a different name. In addition to reverting from "cultural niche construction" to "culture," Whiten et al. (2017:7777) noted, "there is of course a whole discipline of social and cultural anthropology of which, as the name implies, the target of study is culture." Given this realization, either NCT or anthropology would appear to be superfluous.

Likewise, stepping back from the repeated claims of an intellectual linkage with Waddington and Lewontin, in his most recent book, Laland (2017) directly linked the origins of his concepts of what he now calls culture to Darwin. Whiten et al. (2017) also discussed the process of culture extending biology, which appears to be a direct connection back to Dawkin's Extended Phenotype. This interesting turn in the discourse away from the neglected evolutionary process to the already well-acknowledged evolutionary process is a significant sleight of hand. The new narrative of a Darwinian approach to the study of culture is clearly Childean or Processual in a broad sense. Many archaeologists since Childe have embraced Darwinian Evolutionary Theory in their discussions of human culture and adaptation. Criticism towards NCT has been building (Dawkins, 2004; Brodie, 2005; Dickins, 2005; Futuyma, 2017; Gupta et al., 2017; Scott-Phillips et al., 2014; Wallach, 2016), and it is important that scholars in the social sciences critically evaluate their use of NCT and whether it provides a new explanatory framework or whether it simply gives them a new banner to campaign old ideas under.

\section{Origins-of-Agriculture Debates}

NCT has been repeatedly applied to the origins-of-agriculture debate over the past two decades (e.g., Laland et al., 2000, 2001; Odling-Smee et al., 2003). The core premise behind Laland and O'Brien's (2010) first application for this purpose parallels ideas already well recognized in human behavioral ecology, notably optimal foraging theory, claiming that humans will "engage in costly niche construction only when you need to." They then go further, claiming that "agriculture should evolve when the availability or productivity of wild resources is low." Likewise, they support longstanding arguments of population pressure as a driver of innovation, stating: "we might well expect that human population growth will frequently be followed by resource depression, thereby raising the economic value of investment in agriculture" (Laland \& O'Brien, 2010:317; O’Brien \& Laland, 2012:459). While rejecting the population pressure 
argument, Rowley-Conwy and Layton (2011) agreed that NCT explains the origins of agriculture through resource scarcity but, in their case, linked to climate change. In a fascinating theoretical reversal, Smith, an outspoken anti-Human Behavioral Ecologist (Smith, 2012), claimed that an NCT approach "predicts that initial domestication occurred within a context of stable or enhanced resource availability and utilization in the absence of any evidence of resource depression and energy imbalance" (Smith, 2015:239). In fact, further showcasing the lack of unification, Smith (2007, 2011, 2012, 2015) has largely reframed the NCT explanation of the origins-of-agriculture questions to match his preexisting theoretical stance.

The stark contrast between the two claims of what NCT does for the origins-ofagriculture debate does not reflect misuse of the concept or a lack of understanding by any of these prominent scholars, it reflects the lack of NCT to provide explanations for either the Why or How questions. NCT only provides a new set of terms to state what theorists have already been saying (i.e., a brand) and lacks a function as an epistemic tool (Futuyma, 2017). If NCT is all encompassing, it can also evade all attempts to test it, because supporters can continually change their claims. NCT is simply a statement (a truism) and does not provide testable and novel scenarios for understanding the origins of agriculture. In application, the only clear prerequisite for a cultural niche construction approach is that it has to involve culture; therefore, all existing theories of the origins-of-agriculture debates fall under the NCT umbrella. Everything from Childe's Propinquity Model to Hayden's Feasting involves cultural-niche-constructing processes. Likewise, scholars using the NCT approach can claim any theoretical add-ons, such as the population pressure or resource abundance caveats, and still justify it as part of the framework.

The contradictions between the Laland (Laland et al., 2000, 2001; Laland \& O'Brien, 2010; O'Brien \& Laland, 2012) and the Smith (2007), Smith, 2011, Smith, 2012, Smith, 2015; Smith \& Zeder, 2013) application of NCT has set in motion a heated debate, which has, oddly, pitted NCT in opposition to optimal foraging theory (Mohlenhoff \& Codding, 2017; Mohlenhoff et al., 2015; Piperno et al., 2017; Smith, 2012, 2015; Zeder, 2015b, 2018; Wallach, 2016). I see no merit in perpetuating this debate here but encourage interested scholars to read the cited references. What does need to be emphasized is the fact that the debate only considers the Smith version of NCT, not the Laland version. As Laland and O'Brien (2010) have illustrated, NCT can morph to become optimal foraging theory, therefore making it impossible to argue against it — an intellectual moving target. Mohlenhoff et al. (2015:E3093) echoed many others stating, "NCT cannot adequately explain the process of domestication because it lacks a general theory of behavior." Likewise, Codding and Bird (2015:14) point out, "Niche construction is not a theory, but a common biological process. Stating that niche construction explains the origins of agriculture merely restates the question as an answer".

The appeal of NCT in the social sciences appears to be its broad utility, whereas a scholar can use the banner, but not change any of their current theoretical views regardless of what those views are. The relabeling of optimal foraging theory or the reinvention of The Food Crisis in Prehistory without acknowledging a much deeper theoretical history is really only two such examples of the same process occurring in Archaeology. Wallach (2016) contrasted the uses of NCT by both Kuijt and Prentiss (2009) and Rowley-Conwy and Layton (2011); in both cases, the authors claimed to 
use NCT to explain changes in Natufian foraging strategies that led to the origins of agriculture. While the two teams of authors come to contradictory conclusions, Wallach (2016) was more interested in the fact that NCT does not actually explain how or why these cultural changes occurred. More importantly, both papers represent applications of NCT without either set of authors having to change any of their preexisting views of cultural development. There are many examples of advocates of NCT republishing the same ideas that they had published before, with almost no change to the general concept, simply adding the term niche construction.

Arguably, the most overt example of scholars using NCT and appropriating previous theories without referencing earlier scholarship is the dismissal of Rindos's Coevolutionary Mutualism Model. Gremillion and Piperno (2009:618) noted that the concepts that NCT advocates promote are not new, and they go on to point out that coevolutionary models for domestication, as presented by Rindos (1984), already incorporate "anthropogenic habitat modification" as drivers of evolution. Abbo and Gopher (2020) argued that all of these different views follow one intellectual trajectory from Rindos. The application of "gene-culture coevolutionary theory" to the origins-of-agriculture debate by O'Brien and Laland (2011) is in large part a reinvention of Rindos (1984). Smith's $(2007,2016)$ use of NCT overlaps considerably with the ideas of Rindos (1984); although given that Smith does fit NCT into a discussion of earlier archaeological theory, his omission of Rindos may be intentional. Smith (2007:196) saw domestication as arising from "relationships of domestication." Zeder (2016:326) stepped even more into Rindos's shoes by saying that NCT suggests that "Domestication is the result of co-evolutionary mutualisms" but went on in the same article to say that NCT opposes Rindos's view "that domestication arose as a gradual process of symbiotic co-evolution" (Zeder, 2016:335). Zeder did clarify her opposition to Rindos as being part of a larger opposition to the selectionist perspective, as well as the Modern Synthesis and neo-Darwinian Theory. None of these points have anything to do with NCT, per se, but they do illustrate that the bigger arguments all harken back to the Lewontin and Wilson debates or divisions between structuralists and adaptationists. One of the critiques of the Rindosian approach is that it takes away human intentionality in the earliest steps of the domestication process, but given that NCT does not differentiate between conscious and unconscious niche-constructing processes, it cannot address the important question of intentionality (see Spengle, 2020).

Given that archaeologists are not supporting the original Laland approach to the domestication debate, I will quickly explore the opposing Smith application of NCT. Smith (2007) took a reductionist approach, bringing all processes of cultivation under one banner; in his view, everything that humans do can be considered niche construction. He conflated an array of evolutionary selective processes into one simple term, presenting case studies as divergent as the domestication of the dog, bottle gourd, fig, knotweed, banana, or the sunflower. This, in theory, would include processes of hybridization, commensalism, developmental plasticity, all cultivation activities, and harvesting pressure. As Smith (2011:265) put it, "The concept of niche construction solves this problem of too many terms and the associated lack of a global perspective. It not only provides a general label for all forms of human management of wild (and domesticated) species but also offers a single unifying approach for integrating consideration of human and nonhuman modification of ecosystems." In his view, NCT provides a new label and it clumps together many already well-studied cultural and 
biological processes. The Smith reductionist approach has slightly been countered by Zeder (2016, 2017, 2018). While Zeder (2016) does claim that developmental plasticity, predator/prey dynamics, commensalism, and intentional breeding are all nicheconstructing processes, she goes on to later separate certain biological processes from the all-encompassing NCT umbrella. One of the most impressive attempts at pulling together a coherent model for plant domestication in less than a dozen pages was presented by Zeder (2017). In opposition to the all-concepts-under-one-banner approach, she frames (1) biological evolvability, (2) developmental plasticity, (3) pleiotropy, (4) hybridization, and (5) niche construction as different biological processes that worked together to drive evolution under early cultivation. This approach most significantly displays the fact that what these scholars mean when they use niche construction is equivalent to what most evolutionary ecologists would call natural selection or, if one prefers, artificial selection. This approach does not diverge from Darwinian Theory or Selectionism (contra claims by Zeder, 2016, 2017); it simply changes the name of the core mechanism - selection. In fact, all five of these processes are well characterized next to gene flow and genetic drift in Huxley's Modern Synthesis.

Given that there are no set parameters within NCT, beyond the caveat that it must involve the behavior of a living organism, it is important to strip down the add-ons and consider what a strict reading of NCT for the application of the origins-of-agriculture debate would look like. Smith and Zeder (2013) claimed that the domestication of plants and animals is an example of NCT in action, specifically cultural niche construction. This means that humans domesticated plants and animals through culturalniche-constructing processes; in this case, those processes include sickle harvesting, seed saving, sowing, tilling, and burning (among other cultural practices). Therefore, the statement that humans domesticated plants through cultural-niche-constructing processes is equivalent to (1) humans domesticated plants through cultural processes or (2) humans domesticated plants through cultivation. Breaking an argument down to its simplest components helps test its utility; it is evident that NCT does not provide explanations to the Why or How questions, it simply provides a new nomenclature that can be applied to old theories, rebranding them.

\section{The Three Primary Examples}

There are three primary examples used as the main case studies to promote the use of NCT in human contexts (Laland et al., 2000, 2001, 2010; Odling-Smee et al., 2003; Laland \& O'Brien, 2010; O'Brien \& Laland, 2012). All of these processes are repeated ad nauseam in promotional articles of NCT and were heavily studied before the introduction of the NCT terminology, and the likelihood of a gene-culture link in each case was postulated half a century ago (Cavalli-Sforza, 1973). Additionally, as noted earlier, they were already used as the main cases for gene-culture coevolutionary theory and dual inheritance theory before the genesis of NCT. In Laland and O'Brien's (2010) appeal to archaeologists, all of their examples of NCT are cited as coming directly from Durham (1991). I discuss these three concepts here to illustrate how NCT fails to provide testable hypotheses. Given its all-encompassing reach, if one idea is proven wrong, its supporters can just adopt a new idea. 


\section{Lactase Persistence}

The argument for the evolution of lactase persistence as a gene-culture feedback relies on the idea that selection for the persistence allele was so strong that individuals with that trait overpowered the gene pool (Laland \& O'Brien, 2010; Odling-Smee et al., 2003). In a traditional sense, this means that either (1) people with the persistence gene were able to reproduce more or (2) people without the gene were dying more. As the classical story goes, the first agropastoralists arrived in northern Europe with sheep, goat, and cow but did not milk them until the onset of the Secondary Products Revolution in the third millennium BC. At this time, a few Europeans possessing an allele for lactase persistence were able to consume milk, providing additional protein and nutrients, notably vitamin D. Over thousands of years, the humans who could not consume milk, being weaker due to vitamin D deficiency and lack of food, died before reaching childbearing age and their lineages gradually ended. This storybook narrative is, at best, overly simplistic, with many glaring flaws; new data show (1) the lactase persistence allele is absent in most of the world's milk drinkers, and other factors such as gut microflora support milk drinking, undermining the arguments of an extreme advantage for the lactase persistent Europeans. (2) Northern Europeans were consuming large amounts of milk for millennia without the allele, and the earliest farmers to move into Europe were already drinking milk and presumably gaining the nutrient advantages without lactase persistence (Cubas et al., 2020). (3) Mutant populations also arose in southern Europe where vitamin D deficiency would not have been an issue; (4) the allele rapidly evolved in parallel across all regions of Europe over just the past 3000 years (and primarily before 1500 years ago, roughly 70 generations; Malmström et al., 2010; Gerbault et al., 2011; Lacan et al., 2011; Burger et al., 2020). And (5) an intensive grain-based agricultural system was well established throughout the late Iron Age and Roman periods in Europe when this supposed extreme selective pressure occurred (Burger et al., 2020). At the very least, the narrative did not play out as previously thought, and it is likely that there are other evolutionary processes driving these changes in allele frequency, such as the allele riding a demic wave front (Burger et al., 2020).

\section{Sickle Cell Anemia}

The arguments for the sickle-cell $(H b S)$ allele being an example of gene-culture feedback states that West African farmers cleared forests in order to plant yams; hypothetically, this process could have led to "a cascade of consequences" (Laland \& O'Brien, 2010). The cleared forests could have increased standing water (paradoxically in opposition to maintaining humid microenvironments as most forests do), allowing for greater breeding of malaria-carrying mosquitoes (Durham, 1991). McNeill (2001) theorized that malaria was a disease of civilizations, building on the counterintuitive link between irrigation and the creation of marshlands. Scott (2017) recently echoed this idea but ultimately argued for the opposite that farmers originally developed irrigation in order to drain the swamp. The contradictions in Scott's arguments illustrate how speculative this just-so evolutionary story is. The single mutation in a recent farming context argument has really been thrown out for more than two decades, despite its continual reuse in the gene-culture coevolution literature. Sickle cell anemia 
derives from at least four independent mutation events, three in Africa and one in either Arabia or southern India. One estimate suggests that these events occurred between 3000 and 6000 generations ago - ca. 70,000-150,000 years ago (Desai \& Dhanani, 2004). Interestingly, in 1954, when Anthony Allison first linked sickle cell anemia and malaria, he did so on the basis of differences between littoral and high-elevation populations in Kenya. He saw natural environmental factors being the driving forces behind the distribution of the trait in these populations; the farming story came about later with no additional evidence to support it. Recent population genetics work supports his original supposition and also illustrates that the gene was prominent in the lowland populations at least 20,000 years before farming developed in the region, and gene flow leads to a more recent spread to forest populations (Laval et al., 2019). Other recent genetic studies have demonstrated the prominence of malaria-related blood pathologies (thalassemia) in prefarming populations in southeast Asia as well (Vlok et al., 2021).

\section{Hypoxia Adaptations}

The Tibetan hypoxia adaptation example is the most problematic of the three. In addition to relying on the dubious concept of relocational niche construction, i.e., walking along the Qinghai plains, it states that people moving onto the Tibetan Plateau changed their own evolution by causing themselves to experience extreme rates of lateterm fetal mortality. Given that childbirth has an extremely high failure rate in hypoxia environments, the traditional narrative suggests that thousands of years of stillbirths led to the evolution of a suite of new traits, including higher levels of hemoglobin in the blood of Tibetans. Countering this view, archaeological evidence shows that humans have only permanently settled the plateau for roughly 4000 years and really only 3000 in areas above 5000 masl in high-hypoxia environments (Chen et al., 2015). Additionally, genetic studies show that the hypoxia pathway gene, EPAS1, was transferred to humans through a hybridization event with ancient Denisovans (Huerta-Sánchez et al., 2014). Therefore, the process did not occur at all how the traditional models suggested.

\section{The Three Key Examples}

Of the three case studies Laland and O'Brien (2010) used to defend their argument for a need to have NCT in archaeology, none occurred as they had envisioned. However, given that NCT encompasses all human behavior, disproving the case study still does not disprove NCT. For example, a scholar could claim that mating with a Denisovan was a niche-constructing process or that walking onto the Tibetan Plateau was a nicheconstructing process regardless of what the consequences of these actions were. Likewise, even if the demic-wave-front scenario played a role in the original spread of the lactase persistence gene, an NCT supporter could argue that it is still relocational niche construction. The three primary examples exemplify the issues in NCT: (1) They existed as theories before the NCT nomenclature was applied to them; (2) they were adopted into NCT without references to the scholarship of previous scientists who worked on the claims (referencing one secondary source, i.e., Durham, 1991); (3) NCT contributed no novel testable theories to any of the three scenarios; and (4) proving the scenario or model wrong still does not affect the validity of NCT. Additionally, to 
reiterate the point of intentionality, Tibetans did not intentionally expose their population to environments where they would have extreme rates of prenatal mortality; therefore, conflating all conscious and unconscious human behavior under one term seems to undermine the expressed goals of anthropological research.

\section{Are Humans Niche Constructors?}

As a fascinating tactic of debate, some supporters of NCT have repeatedly reframed critiques of the theory's utility, claiming that the critics are arguing against the occurrence of niche-constructing processes (e.g., Feldman et al., 2017; Laland et al., 2016; Odling-Smee et al., 2003). In this article, I am not posing the question of whether niche-constructing processes occur or whether they can be evolutionarily significant; these are not tenable scientific questions. No one would ever dispute the claim that humans modify the environment around them. The question should be: Does the nomenclature of NCT help scholars better understand this process? Ecologists, archaeologists, and evolutionary biologists widely accept that humans are the world's greatest evolutionary force (Hendry et al., 2017; Palumbi, 2001; McDonnell \& Hahs, 2015; Bull \& Maron, 2016; Pelletier \& Coltman, 2018). Scientists across the social sciences, especially archaeologists and anthropologists, are aware of the impacts human cultural practice has on the environment. In fact, I would go so far as to argue that these are core principles in archaeological research and have been for nearly a century (Table 2).

\section{Conclusions}

Evolution is based on networks of causation and feedback — basic Darwinian Theory. In fact, since the foundation of the discipline of ecology in the late 1800s, ecologists have primarily focused on the interrelated nature of organisms and the underlying biotic and abiotic factors that influence the distribution and abundance of species (McIntosh,

Table 2 Suggested points of consideration for developing an NCT for archaeology

1 It is important to consider what NCT contributes to archaeological discussions that earlier iterations, such as gene-culture coevolutionary theory, dual inheritance theory, or ecosystem engineering, cannot.

2 The evolutionary gene-culture feedback mechanism cannot be ignored; otherwise, it is not a discrete evolutionary theory. Therefore, the concept can only be used in cases where culture leads to clear evolutionary change in humans.

3 Evolution is a population phenomenon; therefore, NCT must be thought of as a process occurring on a population scale over long periods of time, not within an individual's experience.

4 There needs to be a way to differentiate between intentional and unintentional niche-constructing processes; clumping all biological processes under one phrase makes it useless in practice for an anthropologist.

5 I suggest that scholars try dropping the term from their writing to see if the sentence retains its meaning, does the nomenclature of NCT help scholars better understand the process they are studying or is it being used as a catchphrase?

6 There needs to be a clear delineation between the concepts of niche construction, culture, and artificial selection - in usage. 
1985). But many proponents of NCT have traditionally claimed that the theory recognizes neglected processes in ecology (Odling-Smee, 2010). Ultimately, what was originally intended as a criticism of overly gene-focused models or simplistic mathematical equations of evolution implemented in the 1960s and 1970s has gradually metamorphosed into a nonunified and highly dynamic theoretical discussion. If the original goal of Lewontin was to increase the general awareness that a simple twovariable mathematical equation cannot explain evolutionary change, then scholars should accept his success and move on to a more useful debate. However, as many other scholars have pointed out, through the gradual morphing of the theory to be allinclusive, advocates of NCT have created an academic niche of their own (Brodie, 2005; Dawkins, 2004; Gupta et al., 2017). Lewontin, echoing Gould, was keen on calling out "Just-so Stories" of evolution (Sterenly, 2007), leaving one to wonder how he feels about his name being attached to the current form of NCT. Additionally, he adamantly campaigned against any attempt at linking genes to behavior, presumably meaning that he would oppose what NCT has become.

In accepting that all social behavior is under the umbrella of NCT, then sociology, anthropology, archaeology, and, arguably, even history are fields of NCT. By combining the words cultural, niche, and construction (e.g., Borenstein et al., 2006; Ihara \& Feldman, 2004; Laland \& O'Brien, 2015), does the resulting phrase have a more profound meaning than the word culture (or cultural adaptation)? By combining the words social, niche, and construction (Saltz \& Foley, 2011), does the meaning diverge considerably from the term social? And by combing the words relocation, niche, and construction (Laland et al., 2016; Odling-Smee et al., 2003), does the meaning change from relocation or simply movement? Is arguing that plants and animals were domesticated via cultural niche-constructing processes equivalent to saying they were domesticated through cultural processes? Does it forward the archaeological agenda to collapse all conscious and unconscious biological and social behaviors and processes of humanity down into one term? Does archaeology no longer have room for the concept of culture? These are questions that all researchers should grapple with for themselves; however, if people choose to continue linking themselves to this academic niche, they should deeply consider the heuristic and epistemic merits. Humans are niche constructors, they are ecosystem engineers, and they are one of the most powerful evolutionary forces on the planet today; archaeologists should not need a new nomenclature to discuss that fact. In essence, have the social sciences neglected to consider the process of culture and have ecologists neglected to consider organisms' behaviors?

\section{Availability of data and materials Not applicable.}

Funding Open Access funding enabled and organized by Projekt DEAL. Research funds and support were provided by the Max Planck Institute for the Science of Human History and the European Research Council, grant number 851102, Fruits of Eurasia: Domestication and Dispersal (FEDD).

\section{Declarations}

Conflict of interest The author declares no competing interests. 
Open Access This article is licensed under a Creative Commons Attribution 4.0 International License, which permits use, sharing, adaptation, distribution and reproduction in any medium or format, as long as you give appropriate credit to the original author(s) and the source, provide a link to the Creative Commons licence, and indicate if changes were made. The images or other third party material in this article are included in the article's Creative Commons licence, unless indicated otherwise in a credit line to the material. If material is not included in the article's Creative Commons licence and your intended use is not permitted by statutory regulation or exceeds the permitted use, you will need to obtain permission directly from the copyright holder. To view a copy of this licence, visit http://creativecommons.org/licenses/by/4.0/.

\section{References}

Abbo, S., \& Gopher, A. (2020). Plant domestication in the Neolithic Near East: The humans-plants liaison. Quaternary Science Reviews, 242, 106412.

Adenzato, M. (2000). Gene-culture coevolution does not replace standard evolutionary theory. Behavioral and Brain Sciences, 23(1), 146-146.

Alberti, M. (2015). Eco-evolutionary dynamics in an urbanizing planet. Trends in Ecology \& Evolution, 30(2), 114-126.

Alberti, M., Marzluff, J., \& Hunt, V. M. (2017). Urban driven phenotypic changes: Empirical observations and theoretical implications for eco-evolutionary feedback. Philosophical Transactions of the Royal Society, B: Biological Sciences, 372(1712), 20160029.

Albuquerque, U. P., do Nascimento, A. L. B., da Silva Chaves, L., Feitosa, I. S., de Moura, J. M. B., Gonçalves, P. H. S., da Silva, R. H., da Silva, T. C., \& Júnior, W. S. F. (2019). A brief introduction to niche construction theory for ecologists and conservationists. Biological Conservation, 237, 50-56.

Baldwin, M. J. (1896). A new factor in evolution. The American Naturalist, 30(354), 441-451.

Blancke, S., \& Denis, G. (2018, Apr 10). Bringing Darwin into the social sciences and the humanities: Cultural evolution and its philosophical implications. History and Philosophy of Life Sciences, 40(2), 29. https://doi.org/10.1007/s40656-018-0195-0.

Boivin, N. L., Zeder, M. A., Fuller, D. Q., Crowther, A., Larson, G., Erlandson, J. M., Denham, T., \& Petraglia, M. D. (2016). Ecological consequences of human niche construction: Examining long-term anthropogenic shaping of global species distributions. Proceedings of the National Academy of Sciences, 113(23), 6388-6396.

Boni, M. F., \& Feldman M. W. (2005). Evolution of antibiotic resistance by human and bacterial niche construction. Evolution 59, 477-491.

Boogert, N. J., Paterson, D. M., \& Laland, K. N. (2006). The implications of niche construction and ecosystem engineering for conservation biology. BioScience, 56(7), 570-578.

Borenstein, E., Kendal, J., \& Feldman, M. (2006). Cultural niche construction in a metapopulation. Theoretical Population Biology 70, 92-104.

Boyd, P., \& Richerson, R. (1985). Culture and the evolutionary process. University of Chicago Press.

Boyd, R., \& Richerson, P. J. (2005). The origin and evolution of cultures. Oxford University Press.

Brodie, E. D. I. (2005). Caution: Niche construction ahead. Evolution, 59(1), 249-251.

Broughton, J. M., Cannon, M. D., \& Bartelink, E. J. (2010). Evolutionary ecology, resource depression, and niche construction theory: Applications to central California hunter-gatherers and Mimbres-Mogollon agriculturalists. Journal of Archaeological Method and Theory, 17(4), 371-421.

Bull, J. W., \& Maron, M. (2016). How humans drive speciation as well as extinction. Proceedings of the Royal Society B 283, 20160600.

Burger, J., Link, V., Blöcher, J., Schulz, A., Sell, C., Pochon, Z., Diekmann, Y., Žegarac, A., Hofmanová, Z., \& Winkelbach, L. (2020). Low prevalence of lactase persistence in Bronze Age Europe indicates ongoing strong selection over the last 3,000 years. Current Biology, 30(21), 4307-4315.e13.

Buser, C. C., Newcomb, R. D., Gaskett, A. C., \& Goddard, M. R. (2014). Niche construction initiates the evolution of mutualistic interactions. Ecology Letters, 17(10), 1257-1264.

Cavalli-Sforza, L. (1973). Some current problems of human population genetics

Cavalli-Sforza, L. L., \& Feldman, M. W. (1981). Cultural transmission and evolution: A quantitative approach. Princeton University Press. 
Ceballos, G., Ehrlich P, R., RavenP. H. (2020). Vertebrates on the brink as indicators of biological annihilation and the sixth mass extinction. Proceedings of the National Academy of Sciences 117(24), 13596-13602. https://doi.org/10.1073/pnas.1922686117.

Chen, F. H., Dong, G. H., Zhang, D. J., Liu, X. Y., Jia, X., An, C.-B., Ma, M. M., Xie, Y. W., Barton, L., \& Ren, X. (2015). Agriculture facilitated permanent human occupation of the Tibetan Plateau after $3600 \mathrm{BP}$. Science, 347(6219), 248-250.

Childe, V. G. (1936). Man makes himself. Watts and Co..

Codding, B.F. \& Bird D. W. (2015). Behavioral ecology and the future of archaeological science. Journal of Archaeological Science 56, 9-20.

Connelly, B. D., Dickinson, K. J., Hammarlund, S. P., \& Kerr, B. (2016). Negative niche construction favors the evolution of cooperation. Evolutionary Ecology, 30(2), 267-283.

Creanza, N., Fogarty, L., \& Feldman, M. W. (2016). Cultural niche construction of repertoire size and learning strategies in songbirds. Evolutionary Ecology, 30(2), 285-305. https://doi.org/10.1007/s10682-015-97961.

Cubas, M., Lucquin, A., Robson, H. K., Colonese, A. C., Arias, P., Aubry, B., Billard, C., Jan, D., Diniz, M., \& Fernandes, R. (2020). Latitudinal gradient in dairy production with the introduction of farming in Atlantic Europe. Nature Communications, 11(1), 1-9.

Danchin, É., Charmantier, A., Champagne, F. A., Mesoudi, A., Pujol, B., \& Blanchet, S. (2011, Jun 17). Beyond DNA: Integrating inclusive inheritance into an extended theory of evolution. Nature Reviews. Genetics, 12(7), 475-486. https://doi.org/10.1038/nrg3028.

Darimont, C. T., Fox, C. H., Bryan, H. M., Reimchen, T. E. (2015). Human Imapacts: The unique ecology of human predators. Science. 349(6250), 858-60. https://doi.org/10.1126/science.aac4249.

Darwin, C. (1859). On the origin of species by means of a natural selection, or the preservation of favored races in the struggle for life. Murray.

Darwin, C. (1877). The different forms of flowers on plants of the same species. J. Murray.

Darwin, C. (1881). The formation of vegetable mould, through the action of worms: With observations on their habits. D. Appleton \& Company.

Dawkins, R. (1976). The selfish gene. Oxford University Press.

Dawkins, R. (1982). The Extended Pheonotype. Oxford University Press: Oxford.

Dawkins, R. (2004). Extended phenotype-but not too extended. A reply to Laland, Turner and Jablonka. Biology and Philosophy, 19(3), 377-396.

Dennett, D. C. (2017). From bacteria to Bach and back: The evolution of minds. WW Norton \& Company.

Desai, D. V., \& Dhanani, H. (2004). Sickle cell disease: History and origin. The internet journal of hematology, 1(2), 1540.

Dickins, T. (2005). On the aims of evolutionary theory. A book review of Odling-Smee, JJ, Laland, KN \& Feldman, MW (2003). Niche construction: The neglected process in evolution. Evolutionary Psychology, 3, 79-84.

Donohue, K. (2014). Why ontogeny matters during adaptation: Developmental niche construction and pleiotorpy across the life cycle in Arabidopsis thaliana. Evolution, 68(1), 32-47.

Donohue, K., Polisetty, C. R., \& Wender, N. J. (2005). Genetic basis and consequences of niche construction: Plasticity-induced genetic constraints on the evolution of seed dispersal in Arabidopsis thaliana. The American Naturalist, 165(5), 537-550.

Durham, W. H. (1991). Coevolution: Genes, culture, and human diversity. Stanford University Press.

Elton, C. S. (1927). Animal ecology. Sidgwick \& Jackson.

Elton, C. S. (1958). The ecology of invasions by animals and plants. Springer. https://doi.org/10.1007/978-14899-7214-9.

Erwin, D. H. (2008). Macroevolution of ecosystem engineering, niche construction and diversity. Trends in Ecology \& Evolution, 23(6), 304-310.

Feldman, M. W., \& Laland, K. N. (1996). Gene-culture coevolutionary theory. Trends in Ecology \& Evolution, 11(11), 453-457.

Feldman, M. W., Odling-Smee, J., \& Laland, K. N. (2017). Why Gupta et al.'s critique of niche construction theory is off target. Journal of Genetics, 96(3), 505-508.

Fisher, R. A. (1930). The genetical theory of natural selection. Clarendon Press.

Fisher, R. A. (1941). Average excess and average effect of a gene substitution. Annals of Eugenics, 11(1), 5363.

Flynn, E. G., Laland, K. N., Kendal, R. L., \& Kendal, J. R. (2013). Target article with commentaries: Developmental niche construction. Developmental Science, 16(2), 296-313. https://doi.org/10.1111/desc. 12030.

Fodor, J. A., \& Piattelli-Palmarini, M. (2010). What Darwin got wrong. Profile 
Futuyma, D. J. (2017). Evolutionary biology today and the call for an extended synthesis. Interface Focus, $7(5), 20160145$.

Geertz, C. (1973). The Interpretation of Cultures: Selected Essays. Basic Books: New York.

Gerbault, P. (2012). Comments on: O’Brien \& Laland. Current Anthropology, 53, 453-454.

Gerbault, P., Liebert, A., Itan, Y., Powell, A., Currat, M., Burger, J., Swallow, D. M., \& Thomas, M. G. (2011). Evolution of lactase persistence: An example of human niche construction. Philosophical Transactions of the Royal Society, B: Biological Sciences, 366(1566), 863-877.

Godfrey-Smith, P. (2000). Niche construction in biological and philosophical theories. Behavioral and Brain Sciences, 23(1), 153-154.

Gould, S. J., \& Lewontin, R. C. (1979). The spandrels of San Marco and the Panglossian paradigm: A critique of the adaptationist programme. Proceedings of the Royal Society of London, Series B: Biological Sciences, 205(1161), 581-598.

Gremillion, K. J., \& Piperno, D. R. (2009). Human behavioral ecology, phenotypic (developmental) plasticity, and agricultural origins: insights from the emerging evolutionary synthesis. Current Anthropology, 50(5), 615-619.

Gupta, M., Prasad, N., Dey, S., Joshi, A., \& Vidya, T. (2017). Niche construction in evolutionary theory: The construction of an academic niche? Journal of Genetics, 96(3), 491-504.

Haag, T., Santos, A. S., Sana, D. A., Morato, R. G., Cullen Jr., L., Crawshaw Jr., P. G., De Angelo, C., Di Bitetti, M. S., Salzano, F. M., \& Eizirik, E. (2010). The effect of habitat fragmentation on the genetic structure of a top predator: Loss of diversity and high differentiation among remnant populations of Atlantic Forest jaguars (Panthera onca). Molecular Ecology, 19(22), 4906-4921.

Haeckel, E. (1866). Generelle Morphologie der Organismen. Allgemeine Grundzüge der organischen FormenWissenschaft, mechanisch begründet durch die von C. Darwin reformirte Descendenz-Theorie, etc (Vol. 2)

Hendry, A. P., Gotanda, K. M., \& Svensson, E. I. (2017). Human influences on evolution, and the ecological and societal consequences. Philosophical Transactions of the Royal Society, B: Biological Sciences, 372(1712), 20160028. https://doi.org/10.1098/rstb.2016.0028.

Huerta-Sánchez, E., Jin, X., Bianba, Z., Peter, B. M., Vinckenbosch, N., Liang, Y., Yi, X., He, M., Somel, M., \& Ni, P. (2014). Altitude adaptation in Tibetans caused by introgression of Denisovan-like DNA. Nature, 512(7513), 194-197.

Hui, C., Li Z, Z., \& Yue, D, X. (2004). Metapopulation dynamics and distribution and environmental heterogeneity induced by niche construction. Ecological Modelling 177, 107-118.

Humboldt, A. v., Bonpland, A., \& Jackson, S. T. (2008 [1807]). Essay on the geography of plants. University of Chicago Press.

Hutchinson, G. E. (1957). Cold spring harbor symposium on quantitative biology. Concluding remarks, 22, $415-427$.

Hutton, J. (1788). Theory of the earth, or, an investigation of the laws observable in the composition, dissolution and restoration of land upon the globe / by James Huttonread March 7 and April 4, 1785. Edinburgh : The Society

Ihara, Y., \& Feldman, M. W. (2004). Cultural niche construction and the evolution of small family size. Theoretical Population Biology, 65(1), 105-111.

Ingold, T. (2007). The trouble with 'evolutionary biology'. Anthropology Today, 23(2), 13-17.

Jones, C. G., Lawton, J. H., \& Shachak, M. (1994). Organisms as ecosystem engineers. In Ecosystem management (pp. 130-147). Springer.

Jones, C. G., Lawton, J. H., \& Shachak, M. (1997). Positive and negative effects of organisms as physical ecosystem engineers. Ecology, 78(7), 1946-1957.

Jones, C. G., Gutiérrez, J. L., Byers, J. E., Crooks, J. A., Lambrinos, J. G., \& Talley, T. S. (2010). A framework for understanding physical ecosystem engineering by organisms. Oikos, 119(12), 1862-1869.

Kendal, J., Tehrani, J. J., \& Odling-Smee, J. (2011). Human niche construction in interdisciplinary focus. Philosophical Transactions of the Royal Society, B: Biological Sciences, 366(1566), 785-792. https://doi. org/10.1098/rstb.2010.0306.

Kuijt, I., \& Prentiss, A. M. (2009). Niche construction, macroevolution, and the Late Epipaleolithic of the Near East. In Macroevolution in human prehistory (pp. 253-271). Springer.

Lacan, M., Keyser, C., Ricaut, F.-X., Brucato, N., Duranthon, F., Guilaine, J., Crubézy, E., \& Ludes, B. (2011). Ancient DNA reveals male diffusion through the Neolithic Mediterranean route. Proceedings of the National Academy of Sciences, 108(24), 9788-9791.

Laland, K. N. (2017). Darwin's unfinished symphony: How culture made the human mind

Laland, K. N. (2018). How we became a different kind of animal an evolved uniqueness. Scientific American, 319(3), 33-39. 
Laland, K. N., \& Boogert, N. J. (2010). Niche construction, co-evolution and biodiversity. Ecological Economics, 69(4), 731-736.

Laland, K. N., \& O'Brien, M. J. (2010). Niche construction theory and archaeology. Journal of Archaeological Method and Theory, 17(4), 303-322.

Laland, K. N., \& O'Brien, M. J. (2015). Niche construction: Implications for human sciences. Emerging trends in the social and behavioral sciences: An interdisciplinary, searchable, and linkable resource, 1-10

Laland, K. N., Odling-Smee, F. J., \& Feldman, M. W. (1996). The evolutionary consequences of niche construction: A theoretical investigation using two-locus theory. Journal of Evolutionary Biology, 9(3), 293-316.

Laland, K. N., Odling-Smee, F. J., \& Feldman, M. W. (1999). Evolutionary consequences of niche construction and their implications for ecology. Proceedings of the National Academy of Sciences, 96(18), 1024210247.

Laland, K. N., Odling-Smee, J., \& Feldman, M. W. (2000). Niche construction earns its keep. Behavioral and Brain Sciences, 23(1), 164-172.

Laland, K. N., Odling-Smee, J., \& Feldman, M. W. (2001). Cultural niche construction and human evolution. Journal of Evolutionary Biology, 14(1), 22-33.

Laland, K. N., Odling-Smee, J., \& Feldman, M. W. (2005). On the breadth and significance of niche construction: A reply to Griffiths, Okasha and Sterelny. Biology and Philosophy, 20(1), 37-55.

Laland, Kevin N., Boogert, Neeltje J. (2010). Niche construction, co-evolution and biodiversity, Ecological Economics 69(4), 731-736

Laland, K. N., Uller, T., Feldman, M., Sterelny, K., Müller, G. B., Moczek, A., Jablonka, E., Odling-Smee, J., Wray, G. A., \& Hoekstra, H. E. (2014). Does evolutionary theory need a rethink? Nature News, 514(7521), 161-164.

Laland, K. N., Uller, T., Feldman, M. W., Sterelny, K., Müller, G. B., Moczek, A., Jablonka, E., \& OdlingSmee, J. (2015). The extended evolutionary synthesis: Its structure, assumptions and predictions. Proceedings of the Royal Society B: Biological Sciences, 282(1813), 20151019.

Laland, K., Matthews, B., \& Feldman, M. W. (2016). An introduction to niche construction theory. Evolutionary Ecology, 30(2), 191-202.

Laval, G., Peyrégne, S., Zidane, N., Harmant, C., Renaud, F., Patin, E., Prugnolle, F., \& Quintana-Murci, L. (2019). Recent adaptive acquisition by African rainforest hunter-gatherers of the late Pleistocene sicklecell mutation suggests past differences in malaria exposure. The American Journal of Human Genetics, 104(3), 553-561.

Law, W., \& Salick, J. (2005). Human-induced dwarfing of Himalayan snow lotus, Saussurea laniceps (Asteraceae). Proceedings of the National Academy of Sciences, 102(29), 10218-10220.

Lehmann, R. C. (2008) The adaptive dynamics of niche constructing traits in spatially subdivided populations: Evolving posthumous extended phenotypes. Evolution 62, 549-566.

Lewontin, R.C. (1967) Population Genetics. Annual Review of Genetics 1(1), 37-270.

Lewontin, R. C. (1978). Adaptation. Scientific American, 239(3), 212-230.

Lewontin, R. C. (1982). Organism and environment. Learning, development, and culture, 151-170.

Lewontin, R. C. (1983). Gene, organism and environment. Evolution from molecules to men, 273, 285.

Lumsden, C. J., Wilson, E. O. (1981). The coevolutionary process. Genes, mind and culture. Harvard University Press.

Matthews, Blake, De Meester, L., Jones, C, G., Ibelings, B, W., Bouma, T, J., Nuutinen, V., van de Koppel, J., Odling-Smee, J. (2014). Under niche construction: an operational bridge between ecology, evolution, and ecosystem science. Ecological Monographs 84, 245-263. https://doi.org/10.1890/13-0953.1.

Malmström, H., Linderholm, A., Lidén, K., Storå, J., Molnar, P., Holmlund, G., Jakobsson, M., \& Götherström, A. (2010). High frequency of lactose intolerance in a prehistoric hunter-gatherer population in northern Europe. BMC Evolutionary Biology, 10(1), 1-6.

Mayr, E. (1963). Animal species and evolution. Harvard U.P.; Oxford U.P

Mayr, E. (2001). What evolution is. Basic books.

McClure, S. B. (2015). The pastoral effect: Niche construction, domestic animals, and the spread of farming in Europe. Current Anthropology, 56(6), 901-910.

McDonnell, M. J., \& Hahs, A. K. (2015). Adaptation and adaptedness of organisms to urban environments. Annual Review of Ecology, Evolution, and Systematics, 46(1), 261-280.

McIntosh, R. P. (1985). The Background of Ecology: Concept and Theory. New York: Cambridge University Press.

McNeill, J. R. (2001). Something new under the sun: An environmental history of the twentieth-century world (the global century series). WW Norton \& Company. 
Mesoudi, A., Whiten, A., \& Laland, K. N. (2006). Towards a unified science of cultural evolution. Behavioral and Brain Sciences, 29(4), 329-347.

Möbius, K. A. (1870). Ueber Austern-und Miesmuschelzucht und die Hebung derselben an den norddeutschen Küsten: Bericht an Se. Excellenz den Herrn Minister für die landwirthschaftlichen Angelegenheiten. Wiegandt

Möbius, K. A. (1877). Die auster und die austernwirtschaft. Verlag von Wiegandt : Hemple \& Parey

Mohlenhoff, K. A., \& Codding, B. F. (2017). When does it pay to invest in a patch? The evolution of intentional niche construction. Evolutionary Anthropology: Issues, News, and Reviews, 26(5), 218-227.

Mohlenhoff, K. A., Coltrain, J. B., \& Codding, B. F. (2015). Optimal foraging theory and niche-construction theory do not stand in opposition. Proceedings of the National Academy of Sciences, 112(24), E3093E3093.

Moore, J. W. (2006). Animal ecosystem engineers in streams. BioScience, 56(3), 237-246.

Müller, G. B. (2017). Why an extended evolutionary synthesis is necessary. Interface Focus, 7(5), 20170015. https://doi.org/10.1098/rsfs.2017.0015.

Naiman, R. J. (1988). Animal influences on ecosystem dynamics. BioScience, 38(11), 750-752.

Naiman, R. J., \& Rogers, K. H. (1997). Large animals and system-level characteristics in river corridors. BioScience, 47(8), 521-529.

O'Brien, M. J., \& Laland, K. N. (2012). Genes, culture, and agriculture: An example of human niche construction. Current Anthropology, 53(4), 434-470.

O’Brien, M. J., Laland, K. N., Broughton, J. M., Cannon, M. D., Fuentes, A., Gerbault, P., Hurtado, A. M., Kendal, J. R., Layton, R., \& Mackinnon, M. J. (2012). Genes, culture, and agriculture: An example of human niche construction. Current Anthropology, 53(4), 434-470. https://doi.org/10.1086/666585.

O'Brien, M. J., \& Bentley, R. A. (2015). The role of food storage in human niche construction: An example from Neolithic Europe. Environmental Archaeology, 20(4), 364-378.

Odling-Smee, F. J. (2010). Niche inheritance. In M. Pigliucci \& G. Müller (Eds.), Evolution: The Extended Synthesis. MIT Press.

Odling-Smee, F. J., \& Turner, J. S. (2011). Niche construction theory and human architecture. Biological Theory, 6(3), 283-289.

Odling-Smee, F. J., Laland, K. N., \& Feldman, M. W. (1996). Niche construction. The American Naturalist, $147(4), 641-648$.

Odling-Smee, F. J., Laland, K. N., \& Feldman, M. W. (2003). Niche construction: The neglected process in evolution. Princeton University Press.

Okasha, S. (2005). On niche construction and extended evolutionary theory. Biology and Philosophy, 20(1), $1-10$.

Palumbi S. R. (2001). Humans as the world's greatest evolutionary force. Science 293, 1786-1790.

Pelletier, F., \& Coltman, D. W. (2018). Will human influences on evolutionary dynamics in the wild pervade the Anthropocene? BMC Biology, 16(1), 7.

Piperno, D. R., Ranere, A. J., Dickau, R., \& Aceituno, F. (2017). Niche construction and optimal foraging theory in Neotropical agricultural origins: A re-evaluation in consideration of the empirical evidence. Journal of Archaeological Science, 78, 214-220.

Popper, K. R. (1968). Kant's critique and cosmology'in conjectures and refutations: The growth of scientific knowledge. Harper and Row.

Reader, S. M., \& Laland, K. N. (2002). Social intelligence, innovation, and enhanced brain size in primates. Proceedings of the National Academy of Sciences, 99(7), 4436-4441.

Richerson, P. J., \& Boyd, R. (2008). Not by genes alone: How culture transformed human evolution. University of Chicago press.

Rindos, D. (1984). The origins of agriculture, an evolutionary perspective. Academic Press Inc.

Rowley-Conwy, P., \& Layton, R. (2011). Foraging and farming as niche construction: Stable and unstable adaptations. Philosophical Transactions of the Royal Society, B: Biological Sciences, 366(1566), 849862.

Saltz, J. B., \& Foley, B. R. (2011). Natural genetic variation in social niche construction: Social effects of aggression drive disruptive sexual selection in Drosophila melanogaster. The American Naturalist, $177(5), 645-654$.

Saltz, J. B., \& Nuzhdin, S. V. (2014). Genetic variation in niche construction: Implications for development and evolutionary genetics. Trends in Ecology \& Evolution, 29(1), 8-14.

Schrödinger, E. (1944). What is life?: The physical aspect of the living cell. C.U.P.

Schwilk, D. W. (2003). Flammability is a niche construction trait: Canopy architecture affects fire intensity. The American Naturalist, 162(6), 725-733.

Scott, J. C. (2017). Against the grain: A deep history of the earliest states. Yale University Press. 
Scott-Phillips, T. C., Laland, K. N., Shuker, D. M., Dickins, T. E., \& West, S. A. (2014). The niche construction perspective: A critical appraisal. Evolution, 68(5), 1231-1243.

Segerstrale, U. (1986). Colleagues in conflict: An 'in vivo'analysis of the sociobiology controversy. Biology and Philosophy, 1(1), 53-87.

Shennan, S. (2011). Property and wealth inequality as cultural niche construction. Philosophical Transactions of the Royal Society, B: Biological Sciences, 366(1566), 918-926.

Silver, M., \& Di Paolo, E. (2006). Spatial effects favour the evolution of niche construction. Theoretical Population Biology, 70(4), 387-400.

Slingerland, E. (2012). Integrating science and the humanities: Toward a second wave1. Creating consilience: Evolution, cognitive science, and the humanities, 3-36

Smith, J. M. (1976). A comment on the Red Queen. The American Naturalist, 110(973), 325-330.

Smith, B. D. (2007). Niche construction and the behavioral context of plant and animal domestication. Evolutionary anthropology: Issues, news, and reviews: Issues, News, and Reviews, 16(5), 188-199.

Smith, B. D. (2011). A cultural niche construction theory of initial domestication. Biological Theory, 6(3), 260-271.

Smith, B. D. (2012). Response to Michael J. O’Brien and Kevin N. Laland, Genes, culture, and agriculture: An example of human niche construction, Current Anthropology. 53(4), 434-470

Smith, E. A. (2013). Agency and adaptation: New directions in evolutionary anthropology. Annual Review of Anthropology, 42(1), 103-120.

Smith, B. D. (2015). A comparison of niche construction theory and diet breadth models as explanatory frameworks for the initial domestication of plants and animals. Journal of Archaeological Research, 23(3), 215-262.

Smith, B. D. (2016). Neo-Darwinism, niche construction theory, and the initial domestication of plants and animals. Evolutionary Ecology, 30(2), 307-324.

Smith, B. D., \& Zeder, M. A. (2013). The onset of the Anthropocene. Anthropocene, 4, 8-13.

Spengle, R. N. (2020). Anthropogenic seed dispersal: Rethinking the origins of plant domestication. Trends in Plant Science, 25(4), 340-348.

Spengler, R. N. (2015). Agriculture in the Central Asian Bronze Age. Journal of World Prehistory, 28(3), 215-253.

Steffen, W., Crutzen, P. J., \& McNeill, J. R. (2007). The Anthropocene: Are humans now overwhelming the great forces of nature. Ambio: A Journal of the Human Environment, 36(8), 614-621.

Sterelny, K. (2005). Made by each other: Organisms and their environment. Biology and Philosophy, 20(1), 21-36.

Sterelny, K. (2007). Social intelligence, human intelligence and niche construction. Philosophical Transactions of the Royal Society, B: Biological Sciences, 362(1480), 719-730.

Suess, E. (1904). The face of the Earth (Vol. 1). Claredon Press.

Sullivan, A. P., Bird, D. W., \& Perry, G. H. (2017). Human behaviour as a long-term ecological driver of nonhuman evolution. Nature Ecology \& Evolution, 1(3), 1-11.

Tansley, A. G. (1935). The use and abuse of vegetational concepts and terms. Ecology, 16(3), 284-307.

Townsend, J. M. (2000). Adaptation and intracultural variation. Behavioral and Brain Sciences, 23(1), 162162.

Trigger, B. (1971). Archaeology and ecology. World Archaeology, 2(3), 321-336.

Turner, J. S. (2016). Homeostasis and the physiological dimension of niche construction theory in ecology and evolution. Evolutionary Ecology, 30(2), 203-219.

Van Valen, L. (1973). A new evolutionary law. Evolutionary Theory, 1(1), 10.1126.

Vernadsky, V. I., Grinevald, J., Langmuir, D. B., \& McMenamin, M. A. (1997 [1926]). . Copernicus.

Vlok, M., Buckley, H. R., Miszkiewicz, J. J., Walker, M. M., Domett, K., Willis, A., Trinh, H. H., Minh, T. T., Nguyen, M. H. T., \& Nguyen, L. C. (2021). Forager and farmer evolutionary adaptations to malaria evidenced by 7000 years of thalassemia in Southeast Asia. Scientific Reports, 11(1), 1-15.

Vrba, E. S. (1993). Turnover-pulses, the Red Queen, and related topics. American Journal of Science, 293(A), 418-452.

Waddington, C. H. (1968, 1968/05/01). Towards a theoretical biology. Nature, 218(5141), 525-527. https:// doi.org/10.1038/218525a0

Waddington, C. H. (1969). Paradigm for an evolutionary process. Towards a theoretical biology, 2, 106-128.

Wallach, E. (2016). Niche construction theory as an explanatory framework for human phenomena. Synthese, 193(8), 2595-2618.

Warmington, E. (1909). Oecology of plants: An introd. to the study of plant-communities. Clarendon. 
Waters, C. N., Zalasiewicz, J., Summerhayes, C., Barnosky, A. D., Poirier, C., Gałuszka, A., Cearreta, A., Edgeworth, M., Ellis, E. C., \& Ellis, M. (2016). The Anthropocene is functionally and stratigraphically distinct from the Holocene. Science, 351(6269), aad2622.

Watkins, T. (2017). From Pleistocene to Holocene: The prehistory of southwest Asia in evolutionary context. History and Philosophy of the Life Sciences, 39(3), 22.

West, S. A., El Mouden, C., \& Gardner, A. (2011). Sixteen common misconceptions about the evolution of cooperation in humans. Evolution and Human Behavior, 32(4), 231-262.

Whiten, A., Ayala, F. J., Feldman, M. W., \& Laland, K. N. (2017). The extension of biology through culture. Proceedings of the National Academy of Sciences, 114(30), 7775-7781.

Wilkins, A. S. (2008). Waddington's unfinished critique of neo-Darwinian genetics: Then and now. Biological Theory, 3(3), 224-232.

Wilson, E. (1975). Sociobiology: The new synthesis. Harvard University Press.

Wilson, E. O. (1978). On human nature. Harvard University Press.

Wilson, E. O. (1999). Consilience: The unity of knowledge (Vol. 31). Vintage.

Wollstonecroft, M. M. (2011). Investigating the role of food processing in human evolution: A niche construction approach. Archaeological and Anthropological Sciences, 3(1), 141-150.

Wright, J. P., \& Jones, C. G. (2006). The concept of organisms as ecosystem engineers ten years on: Progress, limitations, and challenges. BioScience, 56(3), 203-209.

Zeder, M. A. (2015a). Core questions in domestication research. Proceedings of the National Academy of Sciences of the United States of America, 112(11), 3191-3198. https://doi.org/10.1073/pnas.1501711112.

Zeder, M. A. (2015b). Reply to Mohlenhoff et al.: Human behavioral ecology needs a rethink that nicheconstruction theory can provide. Proceedings of the National Academy of Sciences, 112(24), E3094E3094.

Zeder, M. A. (2016). Domestication as a model system for niche construction theory. Evolutionary Ecology, $30(2), 325-348$.

Zeder, M. A. (2017). Domestication as a model system for the extended evolutionary synthesis. Interface Focus, 7(5), 20160133.

Zeder, M. A. (2018). Why evolutionary biology needs anthropology: Evaluating core assumptions of the extended evolutionary synthesis. Evolutionary Anthropology: Issues, News, and Reviews, 27(6), 267284.

Publisher's Note Springer Nature remains neutral with regard to jurisdictional claims in published maps and institutional affiliations. 